\title{
The Level of Psychological Burnout at the Teachers of Students with Autism Disorders in Light of a Number of Variables in Al-Riyadh Area
}

\author{
Omar Khalil Atiyat ${ }^{1}$ \\ ${ }^{1}$ Department of Special Education, Faculty of Education, Majmaah University, Saudi Arabia \\ Correspondence: Omar Khalil Atiyat, Department of Special Education, Faculty of Education, Majmaah \\ University, Saudi Arabia. Tel: 966-580-586-149. E-mail: o.mousa@mu.edu.sa
}

Received: May 26, 2017

Accepted: June 15, 2017

Online Published: June 28, 2017

doi:10.5539/jel.v6n4p159

URL: http://doi.org/10.5539/jel.v6n4p159

\begin{abstract}
This study aimed at measuring the level of the psychological burnout in the teachers of students that have autism symptoms in Al-Riyadh area-kingdom of Saudi Arabia. In light of variables. These variables are the gender, the teaching place, the academic qualification of the teachers, the experience of the teachers, the age of the teachers, and the grades that the teachers teach. The methodology adopted in this study was the descriptive surveying method using the "Maslach Burnout Inventory" (MBI) of the psychological burnout. This measure consists of three dimensions as follows: The emotional fatigue, Sagging Feeling, Lack of feeling of personal Achievement. The sample of study included 94 teachers. All of the teachers in the Autism discover symptoms. The result obtained in this study has shown that there is an average level of burnout signs shown by the sample members at all of the three dimensions together. However, the study also showed that the awareness level varied against each dimensions as follows: the lack of feeling the personal achievement - dimension came first with a high average 27.56. In the second, place the (Emotional fatigue) dimension with an average of 23.06. Finally, in the third place came the (sagging feelings) dimension with an average of 3.16. In addition, the results showed significant differences at a level of $\alpha=0.05$ due to the effect of the variables, affecting the burnout level, namely the teachers' gender, the teachers' age, and the teacher's experience. On the other hand, the results showed insignificant differences at the effect of the other variables, which are the teaching place, the teachers' academic qualification, and the age of students with autism disorder.
\end{abstract}

Keywords: teachers of students with autism disorder, psychological burnout, educational services for students with autism disorder, emotional fatigue

\section{Introduction}

Teachers are the prime element in the educational process. That is due to their great effect on teaching students acquiring the skills and behavior and developing them cognitively, psychologically, and socially. This effect is extended to include all the learning stages that the students pass through. Unlike other professions or specialties, the teacher's role is significant and vital because the teacher deals with persons that have their own individual characteristics, which are distinguished in different fields of growth. Based on the conclusive philosophy of the school and the principle of the educational merge which was launched by the modern education theories, the teacher must be able to make a change in the behavior of the learners and deal with all students regardless their cultures ability, or race to achieve the goals of the learning process as well as the desired educational outcomes (Al-Thafri \& Al-Qaryouti, 2010, p. 175). This puts the teachers under a tremendous nervous and psychological pressures which lead to drain the energy of the teacher, and that will result in depriving the teacher from enjoying in his/her life fully. This will cause the teacher to have a negative attitude towards his/herself and towards others, which, in consequence, leads to lack of self-confidence and incompetency in doing a good job. As a result, this leads to quitting the job, which puts the teacher in a state of a psychological burnout (Salam \& Mohammad, 2002, p. 111).

Nowadays, psychological burnout is consider as a major threat for the individual at work. Its effect is much similar to the threats to human's health. Work is a prime means to earn living, fulfill personal needs, and achieve economical stability, social adaptation, mental balance, and personal integration. Therefore, if any disrupt occurs 
at work, a series of serious troubles will initiate leading to bad consequences such as burnout. Psychological burnout may occur because of disruption in the work environment, which that directly caused by the work's nature circumstances and surroundings, along with personal and social sides that determine the type and the amount of responding to these issues (Gold \& Roch, 1999, pp. 52-83).

In the seventies of the late century, the term "psychological burnout" emerged. It became popular because of publishing it by scholars and researchers in conferences and through the media, where they tried to put a clear understanding for this state that hits workers in different kinds of jobs, clarify its causes, and try to either eliminate it or adapt to it. The pioneer in using this term was "Herbert Freudenberg". He used this term to refer to the physical and emotional response to work pressures that appear to workers in humanitarian professions, who tire themselves pursuing hard targets (Al-Masri \& Al-Momen, 2014, p. 302).

The teacher is the main element of the educational process, it is so important that any factor that causes a mental, and nervous pressures must be treated and, if possible, eliminated, so that the teacher can be able to do his job to provide all what his/her students need according to the valid state laws and regulations. These teachers, due to the pressures, are subjected to lack of self confidence that leads the teacher to be disable to do the job in a right manner, which may lead to quit the job for good (Burnsting \& Lane, 2014, pp. 701-702).

Many studies pointed out those workers in the service sectors, particularly teaching, are more likely to suffer from burnout. That is due to the pressures they face, on daily basis, which affects the teacher's motivation and attitude toward his job, tasks, duties (Hoffman \& Palladino, 2007, pp. 19-20). The emotional fatigue syndrome that results from several challenges that face special education teachers is considered as the end of the useless adapting process to the acute stress. The acute stress is a psychological symptom, which appear especially in service-providing professions. These symptoms are caused by the professional stress those workers face in humanitarian services including teachers.

Burnout of teachers can be described as a 3 dimensional syndrome. These dimensions are the emotional fatigue, which occurs when teacher runs out emotions and feels like they are helpless. The other dimension is sagging feelings. It is cancelling out the personal characters, which appear when the teachers pull out from interacting with their students and having bad attitude toward their job and their students too.

The last dimension is the lack of feeling the personal achievement in teachers by looking down on themselves, as they are not up to dealing with their students (Coman et al., 2013). It is worth mentioning that these pressures are increased on the teachers of special education especially when those teachers do not have the appropriate professional and academic training, or not availing the adequate school environment or climate. All these cause the teacher to suffer many psychological pressures. In this case, the teacher must be helped to overcome these obstacles (Fore \& Bender, 2002, p. 37).

Moreover, it is common among educational and psychological researchers that teaching professions is the most in showing psychological burnout, and this requires high efficiency and personal skills to meet their job. Teaching special-need-students is causing, mostly, psychological burnout due to the fact that students with special needs do not change fast or easily which might develop a sense of depression, inefficiency, and disappointment which, by itself, is a source of professional pressure for teacher (kakhen, 1997, p. 2).

Psychological pressure is considered a characteristic of life. It is sometimes, desired at certain level to form an incentive for the worker to increase productivity. If these pressures are increased beyond desired level, they develop hard-to-solve problems for their negative effect on mental and physical health. Therefore, these, pressure must be taken care of adequately to avoid burnout situations.

From this vision, psychological pressures and burnout are, relatively, modern terms that have been discussed in many researches in social psychological and profession psychology. These researches affirmed, in most, that psychology pressures and burnout are profession-problems. They need to be understood by examining the individual's personality and the work environment (Alsheikh, 2002). Al-Zayodi identified psychological burnout as: The psychological state that trouble the individuals who work in jobs that provide social and humanitarian services to others (Al-Zyoudi, 2007).

Both Al- Kharabshah and Arabiyat, defined burnout as a group of symptoms such as neural stress, emotional energy wear-out, stripping personal characters, feeling dissatisfactory about achieving at work which may hit the people who interact with others through work (Al-Kharabshah \& Arabiyat, 2005, p. 279).

Based on the previously mentioned definitions, the term "psychological burnout" emerges in the individual's feeling that his needs are not been fulfilled, and his expectations not achieved accompanied with disappointment. In addition, a group of psychological and physical symptoms appears which leads to low ego, which results in 
loosing self-confidence, the feeling of worry, and tension, tendency to withdrawal, freezing, and giving up. These all are caused by work burdens and not being able to face the job's requirements.

\subsection{Causes of Psychology Burnout}

Teachers may face many problems and hardships at school, which may lead to many psychological pressures, which, possibly, lead to what is scientifically denoted as "psychological burnout". The main factor to this state is the psychological and professional pressures, in addition to other factors such as personality factor associated with the individual, social factors, and work factors. Researchers substantiated all these factors (Abed Al-Ali, 2003, pp. 48-50).

In this regard, a report that was presented to the American National committee pointed out that there was a high shortage in special education, also stated that this kind of teachers are in great demand because they had to do their roles under hard circumstances. This shortage of teachers resulted to hire un-trained, inexperienced, unqualified, and inefficient teachers who don't have the proper skills they should have.

To avoid losing the experienced teachers, field researchers must study the reasons that let these teachers quit working. The most important reasons behind this are the mysterious responsibilities the contradictions, the tiring paper work, the inadequate administrative support, teacher isolations, the difficulty of issuing practice certificates, the inefficient preparing for special education teacher and modern general education (Alkhateeb et al., 2014, p. 46).

\subsection{Autism}

The American Association of psychology defined autism as a development disorder. It's widely spread and showed as malfunction in communication skills hindered social interactions and repetitive pattern behavior (Hammour \& Obaidat, 2013, p. 45). Autistic persons are in coherent group, they differ in mental abilities, social skills, linguistic communication skills, or their sensation responses. The amount of these differences among the autistic person vary from moderate to extreme (Al-Zuriqat, 2010, p. 50).

In addition, many characteristics and features distinguished Autistic students that can be reasons of psychological burnout for their teachers where they face many challenges and hardships upon teaching those students and this can form a major factor of emotional stress symptoms and burnout. These challenges emanate a group of features and attributes of the autistic students. Not any teacher can be a qualified teacher of Autistic students. A successful teacher of Autistic students must pass through a conclusive training and a great guided experience which, consequently, make those teachers possess features that make them able to deal with their students, successfully (Hallahon \& Kauffmann, 2010, p. 670).

Autistic students don't have the opportunity to have the same amount of information that normal students of the same age have. That is because the autistic students suffer lackness of linguistic communication. Other factors are the disability of social interaction, pattern behavior, and repetitive actions contribute to the lack of information in autistic students in comparison with normal students.

All these factors require that the teachers of Autistic students must have a great experience and have many skills, and this causes tremendous pressures, which may lead to suffer a state of burnout (Dawson \& Watling, 2000, p. 418). Therefore, the features and the characteristics of the autistic students put the teachers of autistic students in big challenges and pressures, particularly, when these challenges and pressures come along with unprofessional school environment, unsupportive administration, the absence of cooperative education, lack of interrelationship between the teacher and his colleagues. We conclude that the mentioned factors contribute, in a great manner, to make the autistic children's teachers threatened of burnout considering what they pass through with their students. Any of these factors can hinder the teacher and prevent him/her from doing their job in successfully which affects the students negatively, this, inconsequence will harm the society (Obeidat, 2002, p. 4).

\section{Thesis Problem}

Krapp stated that about half of the workers in the United States of America they subjected, in one way or other, to the symptoms of psychological burnout, along with weak responses toward the pressures they encounter in their work environment. It appears that the burnout affects, in particular, the workers in social, educational, and humanitarian fields. This is due to the, relatively, long periods of time they spend in providing serving efforts. In addition, the poor response of the served people to the specialists' efforts makes the later disappointed and depressed, and the special education teachers are no exception. Particularly, the teachers of autistic students. That is because those teachers' job nature is so unique and distinguished for their teaching, educational and moral responsibilities (Krapp, 2002, pp. 2345-2346). 
In Addition, Chirness said that burnout affects on teachers' spiritual and mental status. It, also, affects the quality of the services presented by the teachers to the students, and the service recipients, which affects the nature of the administrative and educational duties, which harms the services presented in the community programs (Cherniss, 1982, p. 84). The researcher, in this study, sensed the burnout problem because of working as a teacher for several years and as a supervisor of many students in the Bachelor degree during his work. He noticed that the teachers varied in showing enthusiasm for their work.

Education experts agree that teachers must have been a well academically and professionally preparing. Also, they must be able to acquire knowledge and skills in different educational fields to be able to perform their duties toward their students. On the other side, developing the teacher professionally requires prior and within the service. However, some gaps emerge in the process of training special education teachers, especially the teachers of autistic students, which made them, enable to deal with those students (Al-Smadi, 2007, p. 2).

Also, some educationalists pointed out that the training that the students have before graduation is not adequate enough, which makes the new teachers not able to do their jobs well in a fast changing life (Shwayter, 2004, p. 23).

It is worth mentioning that the kingdom of Saudi Arabia, as other developing countries, needs the studies and researches that are concerned with qualifying and training the teachers of students with special needs in general, and autistic students in particular. A few studies targeted preparing the teachers of autistic students before and during the service. Through his field experience, the researcher noticed gaps in teachers' efficiency, in addition to an obvious lack of awareness of the professional component in both theoretical and practical dimensions. Also, a shortage was noticed in teachers' possession of modern training strategies and programming in addition to poor usage of the technological methods. This reflects, in a negative way, on their performance as well as their students' developments. This leads to burnout for the teachers because they will feel helpless in doing their jobs.

This study is based on the idea that autistic students have obstacles regarding growing and developing their personality. Therefore, their teachers face some complications in doing their job. Failing to meet these complications cause teachers not doing their job well. This make them disappointed and depressed which cause a failure in teaching students with autism. This all will result in burnout. Based on all the above, this thesis presents the following questions:

1) How bad can burnout be in the teachers of Autistic students?

2) Is there a significant statistical differences at level $a=0.05$ for burnout and its three dimensions (Emotional fatigue, sagging feelings, and lack of feeling personal achievement) in teachers of autistic students in Al-Riyadh area that are related to variables (the academic qualification, years of experience, teachers' age, stage of teaching)?

\section{Research Importance}

The importance of this study can be in two phases:

- Theoretical importance: The importance of this study lies in the fact that only very few studies handled the problems and hardships that face the teachers of autistic students. Most of previous Arabic studies handled the autistic students and their hardships but not the teachers.

- Applied importance: The applied importance lies in the results that are achieved from this study. These results will contribute to re-consider the programs of preparing the autistic students' teachers. Also, they will lead to reconsider the administrative and financial facilities provided, within school environment, for the teachrs. Therefore, this reduces the risk of burnout. In addition, teachers training programs will be put to develop the teachers and make them able to get rid of negative attitudes.

\section{Research Aims}

The current research aims at recognize the level of burnout in the teachers of students with autism disorders at Al-Riyadh area in light of some demographic variables (the academic qualifications, years of experience, age, grades being taught).

\section{Methodology}

The researcher used descriptive surveying method in order to achieve the goals of the study.

The variables of the study are: 


\subsection{The Independent Variables}

-The academic qualification: which has 3 levels (Diploma, Bachelor of Science, and post graduate studies).

-Years of experience: has 3 levels (1-5 years, 6-10 years, $11+$ years).

-Gender of teacher: has 2 categories (Male/Female).

-Age of teacher: has 3 categories (20-30, 31-40, 41 years old).

-Students age: has 3 categories (below 6 years, 7-12 years, 13-18 years).

-The teaching place: has 3 categories (special education institute, a program within regular school programs).

\subsection{The Dependent Variable}

It is the level of the psychological burnout among the teachers of the Autistic students, in Al-Riyadh Area considering a number of variables, which is obtained by using the tool of study.

\subsection{The Statistical Processing}

To answer the first question, the mean value was calculated along with the standard deviation for answers of the members question according to each dimension of the study.

As for question number two, Autistic student was run to analyze the multiple differences in levels of burnout of the teachers of Autistic students considering the variables of study (Academic qualification, years of experience, teachers gender, age, and grades being taught) to reveal the differences and to what variable they refer.

For unequal groups, The Toki differences Test for dimensional comparison.

\subsection{Study Sample}

The study sample includes all the teachers of autistic students who work in 3 of major Autism centers in Al-Riyadh City, Prince Nasser Ben Abdul-Aziz Autism Center, East of Al-Riyadh Autism Center, and West of Al-Riyadh Autism Center. There are 179 teachers in the centers the study sample consists 93 male and female teachers out of 179 teachers. The teachers responded to the study. Table 1 elaborates the study sample.

Table 1 . The distribution of the study sample members

\begin{tabular}{lll}
\hline \multirow{2}{*}{ Name of the center } & \multicolumn{2}{l}{ No. of teachers of Autistic students } \\
\cline { 2 - 3 } & Male & Female \\
\hline Prince Nasser Ben Abdul-Aziz Autism Center & 15 & 21 \\
East of Al-Riyadh Autism Center & 17 & 14 \\
West of Al-Riyadh Autism Center & 13 & 13 \\
Total & 45 & 48 \\
Grand Total & & 93 \\
\hline
\end{tabular}

\subsection{Tools of the Study}

For researching purpose, the Maslach Burnout Inventory (MBI) used in this study. This measure used to determine the burnout level; used for its stability and high credibility.

In other words, it is so much reliable and suitable for this research .The Maslach Burnout Inventory (MBI) is tool for burnout has two parts:

The first part includes the demographic variables group for study sample (the academic qualification, years of experiences, the gender of the teacher, age, the grades taught) while the second part includes the points of the measure distributed over its 3 dimensions (the emotional fatigue, sagging feelings, lack of feelings of personal achievement).

The responses of the study sample members is tabulated according to the measuring tool according to the measuring tool according to the six-step Likrat Model Table 2 shows the dimensions and the points of the measure. 
Table 2. Distribution of points over measure's dimension

\begin{tabular}{lll}
\hline Dimension & \# Points & Points Distribution \\
\hline Emotional Fatigue & 9 & $1,2,3,6,8,13,14,16,20$ \\
Sagging Feelings & 5 & $5,10,11,15,22$ \\
Lack of feelings of personal achievement & 8 & $4,7,9,12,17,18,19,21$ \\
\hline
\end{tabular}

\subsection{Study Limitations}

This study has had the following limitations:

1) Spatial limitation: This study is made on some institutes and programs of autism in Al-Riadh area-The kingdom of Saudi Arabia.

2) Time limitation: This study is performed in the second semester of the school year 2016-2017.

3) Human Limitations: This study is performed on the teachers of Autistic students.

4) Objective limitations: This study is made to determine the burnout level that the teachers of autistic children exhibit when applying the "Maslach Burnout Inventory" (MBI) with its three dimensions.

\section{Study Terminology}

1) Burnout: by convention, a group of symptoms is represented in a stress of nerves that wears out the emotional energy leaving out the personal characters and feeling of dissatisfaction with the achievment in the professional field. These symptoms, usually, appear in those who deal, in their work, with others (Alkharabsheh \& Arabiat, 2005, p. 302) but in this study, the author defines burnout as the level measured for the teachers of autism disorder students. This measured level is obtained by using the "Maslach Burnout inventory" (IBM) with its three dimensions (emotional fatigue, sagging feelings, and lack of feeling the personal achievement).

2) Autism: it is a growth disorder. It appears in childhood (ages from day one to 8 years old). It causes neurological disorder that affect the brain functions appearing as problem in interaction, social communication, and play activities.

These children respond to things rather than persons, and they show disturbance towards any change in their environment. They, always, repeat physical movements or parts of words (DSMV; American Psychiatric Association, 2014). In current study, Autistic students are a group of students that, officially, they diagnosed as autism disorder according to applied standards. They enrolled to receive services from institutes and programs of autism in Al-Riyadh, Kingdom of Saudi Arabia.

3) Teachers of Students with Autism Disorders: the group of teachers enrolled in the cadres of institutes and programs of autism and officially assigned to teach students with autism disorders by the administration of the educational district and the Department of Special Education in the Riyadh region in the Kingdom of Saudi Arabia.

\section{Previous Studies}

Study of Jennet, Harns, and Mesibor (2003). This study aimed at compare between using two different methods of teaching the Applied Behavior Analysis (ABA) which was used by 34 teachers and the organized teaching method (TEACCH) which used by 30 teachers. The researchers used "Maslach Burnout Inventory" (IBM) level in the teachers of autistic students. Both group showed moderate in addition, neither group showed no differences in teaching efficiency.

Study of Aloteibi (2005). This study aimed at determine the burnout level for the teachers who work in the mental disability centers including the ones who deal with autistic students. The methodology use is the comparison method. The researcher ran a comparison among the teachers of multiple-disabilities, mental-disability and Autism students. This comparison was used to determine which type of the above-mentioned teacher is more likely to suffer burnout in light of a number of variables (experience, availing a supporting teacher, availing support). The study sample consisted of all the teachers of multiple-disabilities and Autistic students in Al-Riyadh City. The result of the study showed that the teachers of students that have multiple-disabilities, Autism disorder, and mental disabled share suffered burnout moderately according to the "Maslach Burnout Inventory" (IBM) in two dimensions of the psychological stress and the feeling of accomplishment however, the level of burnout was low in the sagging feelings dimension. Also, the results showed that the teachers of multiple disabilities student were the least professional, while the teachers of the 
autistics students were the most professional. Also, the results showed differences in burnout degree in favor to the most experienced teachers.

Study of Abu Taweiyleh (2007). This study Aimed at determine the differences in the level of burnout among 240 autistic students' teachers and the teachers of hearing-impairment, visual-impairment, and mentally handicapped students. This study, which was made in Qatar, also aimed at find out if there are any differences that related to the gender of teacher or the type of disability. The results of this study showed that there are statistical differences of level of burnout related to the type of disability and the gender of teacher's variables.

Study of Hurt et al. (2013). This study aimed at recognize the personal attributes related to psychological burnout in the Applied Behavior Analysis (ABA) therapists that work with Autistic students. The study sample consisted 13 therapists who work on one-to-one basis with autistics students. The study used personality features measurement model and the "Masalach Burnout Inventory" (IBM). Results of the study showed a strong relation between hot temper and all dimensions of psychological burnout the relation was directly proportional, i.e., the more the nervousness is, the higher the burnout level. In addition, job satisfaction was directly proportional to with level of rest and inversely proportional to nervousness. Also, the results showed that the personal features affect the job-Satisfaction level and burnout.

Study of Coman et al. (2013). It aimed at find out how far are the teachers of autistic students are committed to the philosophical model adopted when applying pre-school programs. It aimed, also, to monitor the burnout symptoms at the teachers. The study sample consisted of 53 teachers of Autistic students in pre-school programs.

17 of the teachers in the sample, study executed the (TEACCH) Program with their students, while 15 teachers applied the (LEAP) program. Another 21 teachers applied the (HQSEP) program. All the teachers had at least 2 years of experience in the programs applied. The results of the study showed a high level of commitment for the (LEAP) group. Also, the (LEAP and TEACCH) groups showed equal levels in commitment and the level of burnout was the highest in the (LEAP) group them the other groups.

Study of Hassan (2015) which aimed at determine the level of psychological pressures that female teachers of autistic children suffer in the Autism Center in al-Khartoum city. The analytical descriptive approach was used in this study. In addition, to data collection was made by measuring the psychological pressures at the teachers, who were members of a sample study of 46 teachers, 40 of them were tested in an international method. The study showed that the psychological pressures level is high for female teachers of autistic students in Khartoum; in addition, there are statistical differences for the pressures in those teachers according to the variable of age for the 20-29 years old category. Also, there are statistical differences of pressures in the teachers according to the variable of the academic qualification for the first university degree.

\subsection{Comments on the Previous Studies}

Previous studies showed an obvious relation between teaching job, with its pressures, and the psychological burnout, particularly when working with autistic students. It was noticed that the teachers of autistic students showed high level of burnout in comparison with teachers of other disabled students. And the studies of Abu Tawiylah (2007), Otaibi (2005), and Hassan (2005) was made on female teacher, only to measure burnout level while, the Coman (2013) and Jennet (2003) made the research on monitoring the burnout level for the teachers of autistic students. As for Hurt et al. (2013), the study was made on the burnout level in the (ABA) therapists of autistic students. The above-mentioned studies discussed the burnout issue and the psychological pressures on the teachers of autistic students in particular. We notice that all studies did not discuss specifically, for the autistic students' teachers. Therefore, we air in this study to fill this gap. This study will discuss the burnout level in the teachers of autistic students using "Maslach Burnout Inventory" (IBM) which is a measure for psychological burnout considering number of variables, which are the academic qualification, experience, gender of teacher, age, grades being taught.

\section{Results}

The first question of the current study: "what is the level of burnout in the teachers of Autistic students?"

To answer this question the mean value and standard deviation of the sample member answers were calculated according to every dimension of the study dimensions and the total dimension as well. Table 3 demonstrates the results. 
Table 3. The mean value and the standard deviation of burnout level for teachers of autistic students

\begin{tabular}{llllll}
\hline Rank & Dimension & Number & Mean value & Std deviation & Burnout level \\
\hline 2 & Emotional Fatigue & 93 & 23.0645 & 6.41467 & Moderate \\
3 & Sagging feeling & 93 & 3.1613 & 1.80753 & Low \\
1 & Lack of feeling of personal achievement & 93 & 27.5699 & 2.92440 & High \\
\hline
\end{tabular}

To answer this question the mean values and the standard deviations for the results of the teachers of autistic students over the dimensions of the emotional fatigue, the sagging feeling, and the lack of feeling the personal achievement. The results varied where the lack of feeling the personal achievement ranked first-As shown in Table 3 which shows the values of the mean value and standard deviation over 93 members.

The lack of feeling personal achievement showed an average of 27.56 ranked first, followed by emotional fatigue 23.06, while the sagging feelings can last with 3.16.

Question number 2 "are there any differences, statistically at level a= 0.05 for psychological burnout and it is 3 dimensions (namely: the emotional fatigue, the sagging feelings, and the lack of feelings the personal achievement) of the teachers of Autistic students in Al-Riyadh area that relate to the variables of Gender, Teaching place, Academic Qualification, Years of Experience, Grade taught?". To answer this question, an analysis to multiple differences to determine the differences in the levels of burnout for teachers of the Autistic students according to the variables considered in this study (the academic qualification, years of experience, age of the teacher, grades that taught). The following Tables show the obtained results.

\subsection{First: Gender}

Table 4. T-test for independent samples showing the mean value of burnout level considering the gender variable

\begin{tabular}{|c|c|c|c|c|c|c|c|}
\hline Dimension & Gender & No. & Mean value & Std Deviation & Value of $(\mathrm{T})$ & Degree of Freedom & State Indicator \\
\hline \multirow[t]{2}{*}{ Emotional fatigue } & Male & 45 & 27.9556 & 4.31148 & \multirow{2}{*}{10.567} & \multirow{2}{*}{91} & \multirow{2}{*}{0.000} \\
\hline & Female & 48 & 18.4792 & 4.33192 & & & \\
\hline \multirow[t]{2}{*}{ Sagging feeling } & Male & 45 & 3.4000 & 1.51357 & \multirow{2}{*}{1.237} & \multirow{2}{*}{91} & \multirow{2}{*}{0.219} \\
\hline & Female & 48 & 2.9375 & 2.03591 & & & \\
\hline \multirow{2}{*}{$\begin{array}{l}\text { Lack of feeling the } \\
\text { personal Achievement }\end{array}$} & Male & 45 & 26.7556 & 3.09072 & \multirow{2}{*}{2.687} & \multirow{2}{*}{91} & \multirow{2}{*}{0.009} \\
\hline & Female & 48 & 28.3333 & 2.56269 & & & \\
\hline
\end{tabular}

Table 4 showed statistical differences at level $a=5$ in the emotional fatigue dimension in favor of Males, which indicates that males have more emotional stress than females also, the results in some table showed no statistical differences in the sagging feelings and the lack of personal achievement dimensions for both males and females .

\subsection{Secondly: The Place of Teaching}

Table 5. T Test scores of independent differences among the mean value of burnout levels considering the teaching place variable

\begin{tabular}{|c|c|c|c|c|c|c|c|}
\hline Dimensions & Teaching Place & No. & Mean value & Std. Deviation & ( $\mathrm{T}$ ) value & Degree of Freedom & State indicator \\
\hline \multirow[t]{3}{*}{ Emotional fatigue } & Special Education & 61 & 23.3279 & 6.98265 & \multirow{3}{*}{.545} & \multirow{3}{*}{91} & \multirow{3}{*}{.587} \\
\hline & Center & & & & & & \\
\hline & School sub-Program & 32 & 22.5625 & 5.22980 & & & \\
\hline \multirow[t]{3}{*}{ Sagging feeling } & Special Education & 61 & 2.9508 & 1.74572 & \multirow{3}{*}{$-1.562-$} & \multirow{3}{*}{91} & \multirow{3}{*}{.122} \\
\hline & Center & & & & & & \\
\hline & School sub-Program & 32 & 3.5625 & 1.88265 & & & \\
\hline \multirow{3}{*}{$\begin{array}{l}\text { Lack of feeling the } \\
\text { personal } \\
\text { Achievement }\end{array}$} & Special Education & 61 & 27.4098 & 2.83065 & \multirow{3}{*}{$-.727-$} & \multirow{3}{*}{91} & \multirow{3}{*}{.469} \\
\hline & Center & & & & & & \\
\hline & School sub-Program & 32 & 27.8750 & 3.11862 & & & \\
\hline
\end{tabular}


Results shown in Table 5 showed no statistical differences at $\mathrm{a}=0.05$ level in the median of burnout levels at all study dimensions (the emotional fatigue, sagging feelings, and the lack of feeling the personal achievement considering the place of teachings). This indicates that levels of burnout for teachers of Autistic students are almost the same at both institutes and the regular school.

8.3 Third: Age

Table 6. Mean values and standard deviations of the scores of burnout levels based of age variable

\begin{tabular}{lllll}
\hline Dimensions & Age & No. & Mean value & Std. Deviation \\
\hline Emotional fatigue & $20-30$ & 42 & 22.0476 & 5.49923 \\
& $30-41$ & 36 & 22.5556 & 6.34460 \\
& $41+$ & 15 & 27.1333 & 7.72627 \\
& Total & 93 & 23.0645 & 6.41467 \\
Sagging feeling & $20-30$ & 42 & 3.0238 & 1.63032 \\
& $30-41$ & 36 & 2.9722 & 1.87443 \\
& $41+$ & 15 & 4.0000 & 2.00000 \\
Lack of feeling the personal Achievement & Total & 93 & 3.1613 & 1.80753 \\
& $20-30$ & 42 & 26.6905 & 2.65484 \\
& $30-41$ & 36 & 27.4444 & 2.65593 \\
& $41+$ & 15 & 30.3333 & 2.71679 \\
& Total & 93 & 27.5699 & 2.92440 \\
\hline
\end{tabular}

Table 6 shows that the mean value in the emotional fatigue dimension voices between 22.0476-27.1333, while in the sagging feelings 2.9722-4.0000, and in the lack of feeling the personal achievement the mean value was 29.6905-30.3333 overall, taking age into consideration, the mean values varied 3.1613-27.5699.

A singular differences analysis was run to determine the differences of burnout level for the teachers of Autistic students. Table 7 shows the results obtained.

Tables 7. Results of the singular differences analysis for mean values of burnout level considering the age factor

\begin{tabular}{|c|c|c|c|c|c|c|}
\hline Dimensions & Sources of difference & Squares Total & Degree of freedom & Squares Average & $\mathrm{F}$ & Significance \\
\hline \multirow{3}{*}{ Emotional fatigue } & Among groups & 301.086 & 2 & 150.543 & \multirow{3}{*}{3.888} & \multirow{3}{*}{0.24} \\
\hline & Within groups & 3484.527 & 90 & 38.717 & & \\
\hline & Total & 3785.613 & 92 & & & \\
\hline \multirow{3}{*}{ Emotional sagging } & Among groups & 12.632 & 2 & 6.316 & \multirow{3}{*}{1.974} & \multirow{3}{*}{0.145} \\
\hline & Within groups & 287.948 & 90 & 3.199 & & \\
\hline & Total & 300.581 & 92 & & & \\
\hline \multirow{3}{*}{$\begin{array}{l}\text { Lack of feeling the } \\
\text { personal } \\
\text { Achievement }\end{array}$} & Among groups & 147.597 & 2 & 73.799 & \multirow{3}{*}{10.391} & \multirow{3}{*}{0.00} \\
\hline & Within groups & 639.198 & 90 & 7.102 & & \\
\hline & Total & 786.796 & 92 & & & \\
\hline
\end{tabular}

Table 7 showed statistical differences at level $\mathrm{a}=0.05$ in both dimensions: the emotional fatigue and the lack of personal achievement regarding the teacher Age variable, as for the sagging feelings dimension, no statistical differences shown according to the teachers age. To find out the sources of different 5 the Toki test of dimensional comparisons was made among the mean value as shown in Table 8 . 
Table 8. Results of Toki test for dimensional comparison for emotional fatigue and lack of feeling personal achievement considering the age of teachers

\begin{tabular}{|c|c|c|c|c|}
\hline The Independent Variable & Age & Age Category Groups & $\begin{array}{l}\text { Mean value of differences } \\
\text { between age and age categories }\end{array}$ & Significance \\
\hline \multirow[t]{6}{*}{ Emotional Fatigue } & $20-30$ & $31-40$ & $-.50794-$ & .931 \\
\hline & & $41+$ & $-5.08571-*$ & .021 \\
\hline & $31-40$ & $20-30$ & .50794 & .931 \\
\hline & & $41+$ & $-4.57778-^{*}$ & .049 \\
\hline & $41+$ & $20-30$ & $5.08571^{*}$ & .021 \\
\hline & & $31-40$ & $4.57778^{*}$ & .049 \\
\hline \multirow[t]{6}{*}{ Lack of feeling the personal Achievement } & $20-30$ & $31-40$ & $-.75397-$ & .430 \\
\hline & & $41+$ & $-3.64286-*$ & .000 \\
\hline & $31-40$ & $20-30$ & .75397 & .430 \\
\hline & & $41+$ & -2.88889 -* & .002 \\
\hline & 41 & $20-30$ & $3.64286^{*}$ & .000 \\
\hline & & $31-40$ & $2.88889^{*}$ & .002 \\
\hline
\end{tabular}

Table 8 shows the differences between the emotional fatigue average in the category $20-30$ and in the category $41+$ years is 5.0857 which is statistically significant at $\mathrm{a}=0.05$ in favor to the $41+$ years category which indicates higher emotional stress. As for the lack of feeling personal achievement dimension, Table 8 shows a significant statistical differences at a $=0.05$ between the 20-30 category and the $41+$ category in favor to the $41+$ category with a value of 3.6428. That indicates that $41+$ category has a higher level of lack of feeling the personal achievement. Also, the 41 category shows higher level of lack of feeling the personal achievement than the 31-40 category with a value of 2.8889 which has a statistical significance at $\mathrm{a}=0.05$.

\subsection{Fourth: Experience}

The mean value and the standard deviation of the scores of psychological burnout measuring levels

Table 9. The mean value and standard deviation of study sample members at the three dimensions taking into consideration the experience variable

\begin{tabular}{lllcc}
\hline Dimensions & Years of experience & No. & Mean value & Std Deviation \\
\hline Emotional fatigue & $1-5$ & 42 & 22.1905 & 5.74345 \\
& $6-10$ & 37 & 22.6486 & 6.21475 \\
& $11+$ & 14 & 26.7857 & 7.89526 \\
Emotional Sagging & Total & 93 & 23.0645 & 6.41467 \\
& $1-5$ & 42 & 3.0476 & 1.75238 \\
& $6-10$ & 37 & 2.9459 & 1.71506 \\
Lack of feeling the personal Achievement & $11+$ & 14 & 4.0714 & 2.05555 \\
& Total & 93 & 3.1613 & 1.80753 \\
& $1-5$ & 42 & 25.8333 & 2.69522 \\
& $6-11$ & 37 & 28.4595 & 1.80423 \\
& $11+$ & 14 & 30.4286 & 2.79324 \\
\hline
\end{tabular}

The mean value in emotional fatigue varied 22.1905-26.7857, and at the sagging feelings the value was 2.9459-4.0714, while at the lack of feeling personal achievement the value was 25.8333-30.3333. As for the overall median, the value varied 3.1613-27.5699 consideration the years of experience variable we made. The singular difference analysis of the differences of burnout level, considering the years of experience. 
Result are shown in Table 10, Results of analyzing the singular differences for mean value of burnout.

Table 10 . Statistically significant differences at $\mathrm{a}=0.05$ in the lack of feeling personal achievement considering the experience factor

\begin{tabular}{|c|c|c|c|c|c|c|}
\hline Dimensions & Source $s$ of difference & Squares Total & Degree of freedom & Squares Average & $\mathrm{F}$ & Significance \\
\hline \multirow[t]{3}{*}{ Emotional fatigue } & Among groups & 232.347 & 2 & 116.174 & & \\
\hline & Within groups & 3553.266 & 90 & 39.481 & 2.943 & .058 \\
\hline & Total & 3785.613 & 92 & & & \\
\hline \multirow[t]{3}{*}{ Emotional sagging } & Among groups & 13.855 & 2 & 6.928 & & \\
\hline & Within groups & 286.725 & 90 & 3.186 & 2.175 & .120 \\
\hline & Total & 300.581 & 92 & & & \\
\hline \multirow{3}{*}{$\begin{array}{l}\text { Lack of feeling the } \\
\text { personal Achievement }\end{array}$} & Among groups & 270.345 & 2 & 135.172 & & \\
\hline & Within groups & 516.451 & 90 & 5.738 & 23.556 & .000 \\
\hline & Total & 786.796 & 92 & & & \\
\hline
\end{tabular}

To find out the source of the difference the Toki Test of dimensional comparisons among the mean value.

The results are shown in Table 11.

Table 11. Results of Tokay dimensional comparisons among the mean value of levels of burnout considering the teachers' experience variable

\begin{tabular}{llllr}
\hline $\begin{array}{l}\text { The Independent } \\
\text { Variable }\end{array}$ & Years of experience & \multicolumn{1}{c}{$\begin{array}{c}\text { Years of experience } \\
\text { Category Groups }\end{array}$} & $\begin{array}{c}\text { Mean value of differences } \\
\text { between age and age categories }\end{array}$ & Significance \\
\hline Lack of feeling the & \multirow{2}{*}{ 1-5 years } & $6-10$ & $-2.62613-*$ & .000 \\
personal Achievement & & $11+$ & $-4.59524-*$ & .000 \\
& \multirow{2}{*}{$6-10$ years } & $1-5$ years & $2.62613^{*}$ & .000 \\
& & $11+$ & $-1.96911-^{*}$ & .028 \\
& $11+$ & $1-5$ years & $4.59524^{*}$ & .000 \\
& & $6-10$ years & $1.96911^{*}$ & .028 \\
\hline
\end{tabular}

Table 11 shows that the dual differences among the mean value of the 1-5 and 6-10 years of experience categories, 1-5 \&11, and 6-10 \&11+. Have a significant statistical value in favor to $11+$ category which indicates that this category shows higher amount of lack of feeling the personal achievement than the other categories, in other words the more the experience the more the sense of lack of the feeling of personal achievement.

8.5 Fifth: Academic Qualifications

Table 12. The mean value and standard deviation for the levels of burnout considering the academic qualification

\begin{tabular}{lllcc}
\hline Dimensions & $\begin{array}{l}\text { The Academic } \\
\text { Qualifications }\end{array}$ & No. & Mean value & Std Deviation \\
\hline Emotional fatigue & Diploma & 13 & 22.1538 & 5.69863 \\
& Bachelor of Science & 66 & 23.6061 & 6.52069 \\
& Higher studies & 14 & 21.3571 & 6.57041 \\
& Total & 93 & 23.0645 & 6.41467 \\
Emotional Sagging & Diploma & 13 & 3.3077 & .85485 \\
& Bachelor of Science & 66 & 3.0909 & 1.91132 \\
\hline
\end{tabular}




\begin{tabular}{lllll}
\hline & Higher studies & 14 & 3.3571 & 2.02322 \\
& Total & 93 & 3.1613 & 1.80753 \\
Lack of feeling the & Diploma & 13 & 28.1538 & 2.03495 \\
personal Achievement & Bachelor of Science & 66 & 27.1970 & 3.19239 \\
& Higher studies & 14 & 28.7857 & 1.76193 \\
& Total & 93 & 27.5699 & 2.92440 \\
\hline
\end{tabular}

Table 12 showed that the mean value for emotional fatigue was 21.3571-23.6061, was 3.0909-3.3571 for the sagging feelings, and was $27.1970-28.7857$ for the lack of feeling the personal achievement dimension. The total result of all dimensions was 3.1613-27.5699 considering the years of experience variable.

Table 13. The Toki dimensional comparison test was made

\begin{tabular}{|c|c|c|c|c|c|c|}
\hline Dimensions & $\begin{array}{l}\text { Source s of } \\
\text { difference }\end{array}$ & Squares Total & Degree of freedom & Squares Average & $\mathrm{F}$ & Significance \\
\hline \multirow{3}{*}{$\begin{array}{l}\text { Emotional } \\
\text { fatigue }\end{array}$} & Among groups & 70.949 & 2 & 35.474 & & \\
\hline & Within groups & 3714.664 & 90 & 41.274 & .859 & .427 \\
\hline & Total & 3785.613 & 92 & & & \\
\hline \multirow{3}{*}{$\begin{array}{l}\text { Emotional } \\
\text { sagging }\end{array}$} & Among groups & 1.143 & 2 & .571 & & \\
\hline & Within groups & 299.438 & 90 & 3.327 & .172 & .842 \\
\hline & Total & 300.581 & 92 & & & \\
\hline \multirow{3}{*}{$\begin{array}{l}\text { Lack of feeling } \\
\text { the personal } \\
\text { Achievement }\end{array}$} & Among groups & 34.307 & 2 & 17.153 & & \\
\hline & Within groups & 752.489 & 90 & 8.361 & 2.052 & .134 \\
\hline & Total & 786.796 & 92 & & & \\
\hline
\end{tabular}

Table 13 shows that there are statistical at level $a=0.05$ for burnout levels at all the dimensions of study considering the academic qualification overall the table shows that the effect of academic qualification on burnout has no significance.

8.6 Sixth: Student's Age

Table 14. Mean value \& standard deviations of burnout levels considering the student's age

\begin{tabular}{|c|c|c|c|c|}
\hline Dimensions & The Academic Qualifications & No & Mean value & Std Deviation \\
\hline \multirow[t]{4}{*}{ Emotional fatigue } & Less than 6 years & 32 & 23.2188 & 7.33412 \\
\hline & $7-12$ & 49 & 23.0204 & 5.61430 \\
\hline & $13+$ & 12 & 22.8333 & 7.40802 \\
\hline & Total & 93 & 23.0645 & 6.41467 \\
\hline \multirow[t]{4}{*}{ Emotional Sagging } & Less than 6 years & 32 & 2.9375 & 1.83052 \\
\hline & $7-12$ & 49 & 3.2857 & 1.73205 \\
\hline & $13+$ & 12 & 3.2500 & 2.13733 \\
\hline & Total & 93 & 3.1613 & 1.80753 \\
\hline \multirow{4}{*}{$\begin{array}{l}\text { Lack of feeling the } \\
\text { personal Achievement }\end{array}$} & Less than 6 years & 32 & 27.8125 & 3.16674 \\
\hline & $7-12$ & 49 & 27.2857 & 2.89396 \\
\hline & $13+$ & 12 & 28.0833 & 2.42930 \\
\hline & Total & 93 & 27.5699 & 2.92440 \\
\hline
\end{tabular}


Table 14 shows that the mean value of burnout levels considering the emotional stress is $22.8333-23.8333$, the sagging feelings 2.9375-3.2857 and for the lack of feeling the personal achievement is 27.2857-28.0833. As for the total reading for the all dimensions is 3.1613-27.5699 considering the student's age. The test of singular difference test was made to find the source of differences in the levels of burnout of teachers of autistic students the result are shown in Table 15.

Table 15. Results of singular difference analysis of median of burnout levels considering the student's age

\begin{tabular}{|c|c|c|c|c|c|c|}
\hline Dimensions & $\begin{array}{l}\text { Sources } \\
\text { difference }\end{array}$ & Square Total & Degree of freedom & Squares Average & $\mathrm{F}$ & Significance \\
\hline \multirow{3}{*}{ Emotional fatigue } & Among groups & 1.498 & 2 & .749 & \multirow{3}{*}{.018} & \multirow{3}{*}{.982} \\
\hline & Within groups & 3784.115 & 90 & 42.046 & & \\
\hline & Total & 3785.613 & 92 & & & \\
\hline \multirow{3}{*}{$\begin{array}{l}\text { Emotional } \\
\text { sagging }\end{array}$} & Among groups & 2.456 & 2 & 1.228 & \multirow{3}{*}{.371} & \multirow{3}{*}{.691} \\
\hline & Within groups & 298.125 & 90 & 3.313 & & \\
\hline & Total & 300.581 & 92 & & & \\
\hline \multirow{3}{*}{$\begin{array}{l}\text { Lack of feeling } \\
\text { the personal } \\
\text { Achievement }\end{array}$} & Among groups & 9.004 & 2 & 4.502 & \multirow{3}{*}{.521} & \multirow{3}{*}{.596} \\
\hline & Within groups & 777.792 & 90 & 8.642 & & \\
\hline & Total & & 92 & 786.796 & & \\
\hline
\end{tabular}

Table 15 shows that there are no differences of the statistical significance in levels of burnout for all three dimensions related to the student's age variable. In other words, all levels in all dimensions are close to each other considering the autistic student's age.

\section{Discussion}

This study aims at recognize the levels of psychological burnout in the teachers of autistic students in al-Riyadh area considering a number of variables the results obtained when discussing the first question, which was "what is the level of burnout in the teachers of autistic students". Shows that there is a moderate level of burnout in the study sample members in all the dimensions of this study, on the other hand. The results varied in the level of awareness in different dimensions, where they were "high" in the lack of feeling personal achievement dimension, moderate in the emotional fatigue and low in the sagging feelings in other words the lack of feeling personal achievement ranked first, the emotional fatigue second and sagging feelings third.

The researcher explains that there is an average level of burnout in the members of the study sample and that is due to the difference of the characteristics, features and attributes of the persons of the study sample regarding the gender, academic qualification, and years of experience, age and the student's age. As for the dimension of (lack of feeling the personal achievement) being ranked first, this due to the teaching and communicating skills of students that have autism disorder.

This may affect the effectiveness of the positive feedback that the teachers have, or sense, directly from students, from administration or parents. What supports this explanation is the lack of feeling of the personal achievement that all members of the study sample have exhibited. The researcher also explains the emotional fatigue ranked second because of the difference in attributes and features of the sample's members.

He adds that the teacher's age, gender, academic qualification, years of experience, student's age, may form and major factors in the emotional fatigue in a way that the less-experienced teachers are more subjected to the emotional fatigue symptoms for instance.

As for the sagging feelings dimension, the researcher explains that the dimension ranked third, the last, due to the hardness of the teaching job, particularly teaching the autistic students. That is no matter how big are the pressure on those teachers, still they must interact with the students humanly and sentimentally, and with the families as well. Based on that, it is possible to say that results of the first question of this study have agreed with those published in Al-Otaibi study (2005), and Jennet Harris and Misbove study that published in 2003. On the other hand, this study disagreed with Hassan (2015), Abu Tawiylah (2007), Hurt and others (2013), and Coman and others (2013). 
As for the second questions which was: "are there any significant statistical difference at level a $=0.05$ of burnout and its dimensions (emotional fatigue, sagging feelings, and lack of feelings personal achievement) in the teachers of autistic students in Al-Riyadh Educational area related to variables (gender, teaching place, the academic qualification, years of experience ,age of teachers, the grades taught)?". The result showed that there are differences of statistical significance at $\mathrm{a}=0.05$ that is related to the effect of the gender variable in the emotional fatigue in males more than females. That is due to the psychological nature of males due to their impatience, enduring many undesired behaviors shown by autistic male students compared to female autistic students.

Also, the results show no statistical differences in sagging feelings and in lack of feeling the personal achievement. The results were so close in male and female teachers due to the nature of the teaching job and the similarity of pressures on both genders. These results, related to the gender variable, agreed with Abu Tawiyleh (2007), while others studies did not deal with the gender as a variable.

As for the teaching place variable, results show that there are no statistical differences in the burnout level, in the three dimensions, that are related to the variable of the teaching place. This is evident when the close results obtained whether the teaching place is an institute or a special program in a normal school, due to similarity. Of the surrounding circumstances in the places that present special education service to autistic students. This point is an addition to the previous studies sense they did not consider the variable of the teaching place.

As for the teacher's age variable, the result indicate that there are statistical differences in the emotional fatigue and the lack of feeling the personal achievement variables. While no differences appear in the sagging feelings variables. That is because the teachers of age $(41+$ years $)$ are conjugate to big experience which causes emotional fatigue and lack of feeling the personal achievement in addition, the age variable is associated, primarily with the health situation. Because of getting old, individual may develop many diseases, some of them are acute. This, consequently, affects the person emotionally. This leads to loosing capability possessed before which result in lack of feeling personal achievement.

This study agreed in result related to age with Hassan (2015) which indicated differences related to age in the category 20-29. While other studies did not put the age as a variable. As for the years of experience this studies showed differences in lack of feeling personal achievement the category $11+$ years of experience. The more the years of experience the more the lack of feeling in personal achievement. That is because the teacher with high experience has high expectation of achievement with their students regardless the student's nature as Autistic students. The results agrees Otaibi (2005). However, none of other studies mention the experience as a variable.

As for the academic qualification variable, the results show no differences between statistical significance in the level of burnout. This means that all members performances were similar regardless the academic qualification. The author explains that the academic qualification improves the teaching capabilities of the teachers and enhances their skills too. Therefore; they perform in the class without showing any sign of burnout.

This study disagreed with study of Hassan (2015) in regard with the Bachelor of Science degree. No other studies mentioned academic qualification as a variable. As for the students age variable, thus no significant differences and no sign of burnout was detected in all of its dimensions (emotional fatigue, sagging feelings, lack of feeling personal achievement). That is due to the notion that all students with autism disorder symptoms have the same behavior patterns, repetitive actions, and weak interactions with the teachers. Therefore, no matter what the age of Autistic student is; the teachers will deal with them on the same basic and get the same response.

\subsection{Conclusions and Recommendations}

The following are concluded based on the results achieved:

-The teacher of the autistic students demonstrated an average level of burnout.

-There are differences in burnout levels in the emotional fatigue that relate to gender in favor of male teachers.

-There are insignificant differences in burnout levels in all dimensions related to the teacher place variable.

-Differences exist in the emotional fatigue and lack of feeling personal achievement related to the teachers age.

-Differences appear in lack of feeling personal achievement related to variable of experience in favor the (11+ year's category).

-No differences shown in burnout level regarding the academic qualification.

-No differences shown in burnout level regarding the Student's age. 


\subsection{Based on Results We Recommend}

-pay more attention and reconsider the preparing programs for special education teachers before and within services.

-provide the teachers who work in special education field in general and those who works with autistic students in particular the training programs to improve their efficiency and capabilities to deal with autistic students.

-there have to be training courses and workshops that include identifying the most successful treatment programs that are based on scientific researches to be able to apply them on autistic students.

-conducting more surveying studies about the needs of autistic student teachers.

-provide the teachers of the autistics student with entertaining programs incentives, and vacation place to make them more satisfied with their job.

\section{Acknowledgments}

We thank Dr Madhar Alatiyt, Associate Professor, in Albalqa Applied University for assistance with methodology, and, Dr Ghassan K Alatiyat, for his help in translation that greatly improved the manuscript.

\section{References}

Abdat, A. (2002). The relationship between the personal Attributes and spirits of teachers of special education institutions in the West Bank/Palestine (p. 4, Unpublished Master Thesis). Najah National University, College of Graduate Studies, Nablus, Palestine.

Abed Al-Ali, M. A. A.-S. (2003). The Concept of Ego and the impact of some demographic variables and its relation with the psychological Burnout phenomenon of the secondary stage Teachers in Jenin and Nablus Governorates. Faculty of Graduate Studies, Najah National University.

Abu Tawilah, R. (2007). Differences of Psychological Burnout degree between Teachers of Autistic Children and Teachers of Children with visual, implement and Mental disabilities in Qatar (Master Thesis). Amman Arab University for Graduate Studies, Amman Jordan.

Al-Khateeb, J., Al-Smadi, J., Al-Rousan, F., Hadidi, M., Yahya, K., Al-Natour, M., ... Al-Sroror, N. (2011). Introduction of teaching the students with special Education (pp. 234-235). Dar Al fiker for Publication, Amman, Jordan.

Al-Masri, A., \& Moumen, S. (2014). Psychological Burnout among workers with physical impairment students and its relation to some variables. Journal of Education College, Ain Shams University, 38(2), 300-359.

Al-Otaibi, B. (2005). Psychological burnout among teachers working in the institutes of intellectual education "comparative study". Journal of the Faculty of Education Ain Shams, 129.

Al-Zafari, S., \& Qaryouti, I. (2010). Psychological Burnout of teachers of students with learning difficulties in Sultanate of Oman. Jordanian Journal of Educational Sciences, 6(3), 175-190.

Al-Zureiqat, I. (n.d.). Autism, Behavior Diagnosis and Treatment. Dar wael for Publishing and Distribution, Amman, Jordan.

Al-Zyoudi, M. (2007). Sources of Psychological Stress and Psychological Burnout of Special Education Teachers in Al-Karak Governorate and its Relation with Some Variables. University of Damascus Journal, 23(12), 189-219.

American Psychiatric Association. (2014). Diagnostic and statistical manual of mental disorders (5th ed.).Washington, DC: Author.

Brunsting, N. C., Sreckovic, M. A., \& Lane, K. L. (2014). Special education teacher burnout: A synthesis of research from 1979 to 2013. Education and Treatment of Children, 37(4), 681-712. https://doi.org/10.1353/etc.2014.0032

Cherniss, C. (1982). Staff burnout: Job stress in the human services. In Sage studies in community mental health (3rd ed.). New York, Sage publication Inc.

Coman, D., Alessandri, M., Gutierrez, A., Novotny, S., Boyd, B., Hume, K., ... Odom, S. (2013). Commitment to Classroom Model Philosophy and Burnout Symptoms among High Fidelity Teachers Implementing Preschool Programs for Children with Autism Spectrum Disorders. Journal of Autism and Developmental Disorders, 43, 345-360. https://doi.org/10.1007/s10803-012-1573-1 
Dawson, G., \& Watling, R. (2000). Intervention to facilities auditory, visual and motor integration in autism: A review of evidence. Journal of Autism and Developmental Disorders, 30(5), 113-119. https://doi.org/10.1023/A:1005547422749

Fore, C., Martin, C., \& Bender, W. N. (2002). Teacher burnout in special education: The causes and the recommended Solutions. The High School Journal, 86(1), 36-44. https://doi.org/10.1353/hsj.2002.0017

Gold, R., \& Roth, A. (1999). Teachers managing stress and preventing burnout: The professional health solution. London: Flamer Press.

Haimour, A., \& Obaidat, Y. (2013). "School teachers" knowledge about autism in Saudi Arabia. World Journal of Education, 3(5), 45-56. https://doi.org/10.5430/wje.v3n5p45

Hallahan, D., \& Kauffman, J. (2010). Exceptional Learners: An Introduction to Special Education (pp. 245-250). Pearson education Inc., published as Allen \& Bacon.

Hassan, M. M. (2015). Psychological pressures of Teachers in Autism Centers of Al-Khartoum and its relationship with some variables (Master Thesis). Sudan University of Science and Technology, College of Graduate Studies, Khartoum, Sudan.

Hoffman, S., \& Palladino, J. (2007). Compassion Fatigue as a Theoretical Framework to Help Understand Burnout among Special Education Teachers. Journal of Ethnographic \& Qualitative Research, 2, 15-22.

Hurt, A., Lann, C., Lann, G., Malesky, A., \& McCord, D. (2013). Personality Traits Associated with Occupational "Burnout" in ABA Therapists. Journal of Applied Research in Intellectual Disabilities, 26, 299-308. https://doi.org/10.1111/jar.12043

Jennett, H., Harris, S., \& Mesibov, G. (2003). Commitment to Philosophy, Teacher Efficacy, and Burnout among Teachers of Children with Autism. Journal of Autism and Developmental Disorders, 33(6), 583-593. https://doi.org/10.1023/B:JADD.0000005996.19417.57

Kharabsheh, A. A., \& Ahmed. (2005). Psychological Burnout of workers with students with learning disabilities and resources rooms. Umm Al Qura University for Educational. Social and Human Sciences, 17(2), 293-301.

Krapp, K. (2002). The gale encyclopedia of nursing \& Allied health (Vol. 4). New York, the gale group Inc.

Kuhon, K. (1997). The professional pressures faced by teachers of special education institutions in the West Bank (Unpublished Master Thesis). An-Najah National University, Nablus-Palestine.

Salam, B., \& Muhammad, M. (2002). Study of the relationship between psychological Burnout and Personal Attributes of Individual and Group Games Trainers. The Psychological and Educational Research Journal, 1, 107-127.

Sheikh, D. (2002). The psychology of the relationship between Professional Satisfaction and Psychological Burnout. Arab Journal of Education, 22(2).

Shwiter, I. (2004). Development of training program based on the Educational Learning Competencies to prepare the teachers of social studies for the secondary stage in Jordan and its impact on their practices for those who have competencies (p. 28, Unpublished Ph.D. thesis). Amman Arab University, Amman, Jordan.

Smadi, O. (2007). Effectiveness of Training Program for Teachers of Deaf and Hearing disables students during their Service in light of their Training Needs in Jordan (p. 2, unpublished PhD thesis). Amman Arab University for Graduate Studies, Amman, Jordan.

\section{Copyrights}

Copyright for this article is retained by the author(s), with first publication rights granted to the journal.

This is an open-access article distributed under the terms and conditions of the Creative Commons Attribution license (http://creativecommons.org/licenses/by/4.0/). 